\title{
The Choice of Forest Site for Recreation: A Revealed Preference Analysis Using Spatial Data
}

\author{
Fitalew Agimass ${ }^{\mathrm{a}, \mathrm{b}^{*}}$, Thomas Lundhede $\mathrm{a}^{\mathrm{a}, \mathrm{c}, \mathrm{d}}$, Toke Emil Panduro ${ }^{\mathrm{a}}$, Jette Bredahl Jacobsen ${ }^{\mathrm{a}, \mathrm{c}}$ \\ a Department of Food and Resource Economics, University of Copenhagen, Rolighedsvej 23, 1958 Frederiksberg C, Denmark \\ ${ }^{\mathrm{b}}$ School of Environment, Natural Resources and Geography, Bangor University, Gwynedd, LL57 2UW, United Kingdom \\ ${ }^{\mathrm{c}}$ Center for Macroecology, Evolution and Climate, University of Copenhagen, Rolighedsvej 23, 1958 Frederiksberg C, Denmark \\ ${ }^{\mathrm{d}}$ Centre for Environmental Economics and Policy in Africa, Department of Agricultural Economics, Extension and Rural Development, \\ University of Pretoria, South Africa \\ * Corresponding author
}

\begin{abstract}
In this paper, we investigate the factors that can influence the site choice of recreation. Relevant attributes are identified by using spatial data analysis from a questionnaire asking people to indicate their most recent forest visits by pinpointing on a map. The main objectives of the study are 1) to examine the preferences of visitors for different forest attributes using data from actual visits and 2) to illustrate how many alternative sites needs to be considered for estimation in case of a large number of potential recreational sites. Estimation is performed using a conditional logit as well as a random parameter logit model. The variables that are found to affect the choice of forest location include: distance, forest area, tree species composition, forest density, availability of historical sites, terrain differences, and state ownership. Regarding the second research objective, we empirically show the possibility of getting consistent parameter estimates through random selection of alternatives. We find that increasing the number of alternatives increases consistency of parameter estimates.
\end{abstract}

\section{Keywords}

Discrete choices; forest recreation; revealed preference; spatial data; sampling of alternatives. 


\section{Introduction}

Forests provide a multitude of ecosystem services to society, and recreation has become an important part of that, especially to modern urban lives (Douglass 1982). In Denmark, forest recreation is considered as one of the main leisure activities (Jensen and Koch 2004, Skov-Petersen and Jensen 2004). Therefore, it becomes apparent that the values of such services needed to be taken into account in forest management decisions so as to enhance social welfare. The non-market forest benefits can be estimated using either stated preference (SP) or revealed preference (RP) approaches. The SP approaches have become popular and widely used in the valuation of environmental goods. But, the requirement of a hypothetical market setting remains a major drawback (Hausman 2012) and the use of RP data may be considered as a better option. Estimations based on RP data can be used to validate findings from SP methods, for accurate prediction of choice behaviour with regard to changes in specific policy initiatives, and to support practical management decisions (Haener et al. 2001).

The application of RP methods for environmental valuation requires the use of spatial data to identify site specific characteristics. Moreover, spatial data is quite useful in evaluating preference heterogeneities due to the spatial allocation of environmental goods/services (Horne et al. 2005, Campbell et al. 2008, Hynes et al. 2008, Termansen et al. 2008). As a result, spatial data have received quite considerable attention in previous RP valuation studies, e.g. in forest recreation (see Termansen et al. 2004, 2008, Baerenklau et al. 2010, Abildtrup et al. 2013, Termansen et al. 2013, Abildtrup et al. 2014). Furthermore, understanding the spatial factors affecting non-market values can help providing essential information to decision makers (van der Horst 2006, Campbell et al. 2008).

The analysis of preferences and identification of the determinants of forest recreational sites may help to elaborate on what aspects should be considered in the management and planning decisions. In Denmark, the national forest program has set out a multitude of objectives, one of which is increasing recreational accessibility of forests to the public (DFNA 2002, Zandersen et al. 2007). It is clearly outlined that the aim is to promote forest management and afforestation plans that take account of recreation (DFNA 2002). The afforestation plan is also to expand the forest cover, from the current level of $14 \%$ to $20-25 \%$ in the next 80 to 90 years.

In the present paper, we examine preferences for the different attributes of forest recreational sites using spatial data corresponding to three last forest visits. The last visited forest sites are obtained from a web based survey where respondents were asked to pinpoint both their departure and destination sites $^{1}$ on an interactive google map. Then, forest sites along with different characteristics are identified using publicly available geographical information system (GIS) data, from various sources.

\footnotetext{
${ }^{1}$ The survey also contained a stated preference part.
} 
The study contributes to the existing literature in a number of ways. First, we identify relevant factors important for forest recreation. These include forest area, forest area form (shape), stand density, proportion of dominant species type, presence of nearby nature features (e.g. wetlands and lakes), terrain difference (slope of landscape), presence of historical sites, and a dummy for state ownership. Second, the study relies on higher resolution data than earlier studies and with a wider spatial coverage of survey data in Denmark, allowing for more detailed modelling and validation of earlier studies (Skov-Petersen 2002, Termansen et al. 2004, Termansen et al. 2008, Termansen et al. 2013). Such data, however, result in many forest site observations which require reducing strategies when analysing the choice of a given site. Therefore, the third contribution is to evaluate two modelling assumptions based on convergent validity; namely the validity of random sampling to reduce the number of alternative sites and an identification of the sufficient number of alternatives to include.

The remaining part of the paper is organized as follows. In the next section, we outline factors identified in the literature that influence preferences and the determinants of recreational value of a forest. In the third section, we examine previous research findings with respect to forest recreational practices in the Danish context. In the fourth section, we elaborate our data collection procedures, spatial data organization, and the methodological approach. The fifth section presents estimation results with interpretation of parameter estimates. Finally, we wind up with sections on discussion and conclusion of main findings.

\section{Determinants of forest recreational values}

The factors that affect the recreational value of forest sites are related to the characteristics of the sites i.e. forest attributes on the one hand, and to the visitors' characteristics on the other. First, the structural characteristics of the forest, nature area features, recreational facilities, and infrastructures are considered as the main factors influencing choice of forest site (see e.g. Christie et al. 2007, Termansen et al. 2013, Giergiczny et al. 2015). On the other side, the visitors' socioeconomic and demographic factors as well as recreational activities and purposes have been found to significantly affect both recreational demand and preferences (see Abildtrup et al. 2014, Giergiczny et al. 2015).

Many studies have shown the importance of forest structural characteristics affecting recreational preferences of individuals (see Boxall et al. 1996, Hörnsten and Fredman 2000, Scarpa et al. 2000b, a, Horne et al. 2005, Christie et al. 2007, Nielsen et al. 2007, Petucco et al. 2013, Filyushkina et al. 2017). Forest structural characteristics may consist of species composition, age structure, forest density, vegetation cover, its area, and so on. Edwards et al. (2012a) used a Delphi study to investigate the forest characteristics that affect recreational benefits and identified twelve characteristics being useful; of which the size of trees, size of clear-cuts, and presence of residues are the most important while the number of tree species is the least. Other studies (e.g. Nielsen et al. 2007, Abildtrup et al. 2013, Termansen et al. 2013, Filyushkina et al. 2017) considered 'species 
composition' as one of the main variables; and found mixed or broadleaved forests preferred to coniferous types. In addition, the number of tree species has been found to positively impact the recreational value of a forest (Giergiczny et al. 2015, Filyushkina et al. 2017). A number of studies have also shown the importance of age structure (see Ribe 1989, Lindhagen and Hörnsten 2000, Tahvanainen et al. 2001, Nielsen et al. 2007, Gundersen and Frivold 2008, Edwards et al. 2012b, Giergiczny et al. 2015, Filyushkina et al. 2017). Forests comprising of older trees are preferred over younger ones and the uneven aged stands are better than even-aged stands. In general, the common understanding is that diversity in species composition and age structure positively contributes to the recreational value of a forest (Axelsson-Lindgren and Sorte 1987, Bujosa and Riera 2009, Dhakal et al. 2012, Edwards et al. 2012b, Filyushkina et al. 2017).

Furthermore, many studies have indicated the positive impact of forest size and the landscape's scenic view i.e. from a topographic perspective (see Termansen et al. 2004, Bujosa and Riera 2009, 2010, Termansen et al. 2013). Similarly, openness for visual penetration (which is related to the density of stand trees), ground vegetation cover, and presence of dead woods have been found to impact the recreational value. In some studies (e.g. Kaplan and Kaplan 1989, Bjerke et al. 2006, Heyman et al. 2011), semi-open forests are considered to provide better view and sense of safety than dense forests. In contrast, ground vegetation cover and amount of residues negatively impact preferences (Edwards et al. 2012a, Giergiczny et al. 2015). On the other hand, Bjerke et al. (2006) showed a positive contribution of moderate vegetation cover on recreational preferences. Similarly, the presence of deadwoods which can be associated with biodiversity functions affects recreational value positively (Nielsen et al. 2007, Giergiczny et al. 2015). Forests which are managed to maintain natural processes and associated biodiversity functions are found to have better recreational values (Campbell et al. 2013, Bartczak 2015).

The recreational value of a forest can also be determined by the presence of (or closeness to) other nature area features - for complementary recreational activities. These can include presence of different landscapes (Bujosa and Riera 2009, Giergiczny et al. 2015), or closeness to water bodies and coastal lines (Boxall et al. 1996, Termansen et al. 2004, Abildtrup et al. 2013). In general, the availability of such features increases the recreational value of a forest.

Accessibility is another important factor that affects the recreational value of forests. Distance to the forest (usually from residential location) is the most important factor in the decision to take recreational trips (Hörnsten and Fredman 2000, Smink 2011). People with a shorter distance to forests will have the opportunity to make more recreational trips than those farther away. For instance, two thirds of forest recreational trips in Denmark are taken in areas close to residential neighbourhoods and about $75 \%$ of visitors travel only within a distance of $10 \mathrm{~km}$, considering all transport modes (Jensen and Koch 2004, Termansen et al. 2004, Smink 2011). In Sweden where $60 \%$ of land area is covered with forests, the majority of the population indicate their desire to have short 
travel distance to forests i.e. to be within $1 \mathrm{~km}$ from their residential location (Hörnsten and Fredman 2000). As a consequence, forests closer to urban areas are found to be intensively used for recreation (DFNA 2002, Arnberger 2006). On the other hand, some forest visitors may also be trading off distance and go farther to avoid congestion effects and user conflicts (Bakhtiari et al. 2014).

Availability of recreational facilities like picnic sites, educational paths, and parking lots can also impact the recreational benefits of forests. For instance, forests with hiking paths and picnic facilities have more recreational benefits than forests without such facilities (Christie et al. 2007, Abildtrup et al. 2013, Abildtrup et al. 2014, Giergiczny et al. 2015). Similarly, Termansen et al. (2004) found a positive effect of parking facilities in Danish forests. Availability of good infrastructures (e.g. access to main roads) are also important in contributing for the recreational use of forests (Bujosa and Riera 2009). According to Christie et al. (2007), identifying recreational facilities is essential to meet the requirements of different user groups and increase recreational value of a given site.

On the demand side, it is common to consider socioeconomic and demographic variables as main determinants of outdoor recreation. For instance, Bujosa and Riera (2010) examined variables such as income, number of children, education, and others to determine the demand for forest recreational trips. It is also common to incorporate such variables to account for preference heterogeneity between individuals (see Giergiczny et al. 2015). Another important factor which can affect the site choice is the mode of transport used in outdoor recreation (Termansen et al. 2013, Abildtrup et al. 2014). For instance, forest visitors who used personal cars can travel relatively farther away to visit high quality forests compared to visitors who travel on foot (Abildtrup et al. 2014).

While there are RP studies in between, most of the above literature treats preferences in a SP setting. This study adds to the literature by investigating if the same results can be found in a RP setting. Moreover, our use of high resolution spatial data helps to identify site specific forest attributes, hence avoiding potential biases by aggregation of data.

\section{Forest recreation in Denmark}

Forest cover in Denmark is relatively small compared to most European countries (Bell et al. 2007). It takes up about $14 \%^{2}$ of the total land area of the country. For Danes, recreation in forests is an important aspect of their leisure activities. More than $90 \%$ of the population visit forests at least once a year, with a conservative estimate of $60-70$ million annual visits (Jensen and Koch 2004). The majority of visitors spend one to two hours recreating in a forest per trip (Jensen and Koch 2004). Distance is found to play a substantial role in

\footnotetext{
${ }^{2}$ (http://eng.svana.dk/nature/forestry/ 2017)
} 
affecting the choice of forest site and also in determining the number of annual trips (Jensen and Koch 2004, Termansen et al. 2004, Smink 2011).

So far, many studies have been undertaken, in the Danish context, to assess the recreational value of forests. The national surveys on forest recreation conducted in 1976-1978 and repeated in 1993-1995 (see Jensen and Koch 2004) have contributed a lot. The surveys have been undertaken using questionnaires collected from onsite, car-borne recreation at selected recreational sites. These studies mainly focused on assessing recreational value of forests with an emphasis on the role of forest management (Jensen and Koch 2004, Termansen et al. 2004, Zandersen et al. 2007, Termansen et al. 2008, 2013). The studies have also examined public preferences and recreation demand for specific sites (e.g. Termansen et al. 2004, 2013). Moreover, intensive investigations are undertaken on spatial substitution effects and visitors' preferences (Termansen et al. 2004, 2008, 2013). High resolution spatial data were collected to identify forest characteristics. They found that different forest characteristics - including forest area, fraction of broadleaved coverage, distance to coastal lines, and presence of nature (semi-nature) areas influencing recreational preferences. Other studies have been conducted to analyse preferences of forest visitors using survey data in SP techniques e.g. using choice experiments (see Nielsen et al. 2007, Jacobsen and Thorsen 2010, Bakhtiari et al. 2014, Filyushkina et al. 2017).

In the present study, we add to the case specific literature by using a much higher data resolution, allowing for a more detailed preference elicitation. We have also looked into preference heterogeneities by considering factors such as mode of transport and recreational activities or purposes.

\section{Materials and Method}

\subsection{Sampling and data organization}

In a web based survey, we asked respondents about their previous forest recreation experiences. In addition, they were asked to pinpoint their three most recent forest visits on the map, corresponding to their departure and destination sites. The survey was conducted online from May $19^{\text {th }}$ to June $8^{\text {th }} 2015$ administered by a surveying company where members of a panel of respondents were invited. The participants were rewarded gifts for filling out the questionnaire.

A total of 3,665 individuals accepted the invitation to participate. However, 1339 respondents were prescreened and excluded from the sample, before answering all parts of the questionnaire, to ensure representativeness of the sample in terms of socioeconomic and demographic variables. The sample was further reduced by 1217 respondents as they were not able to complete the questionnaire or fill out the questionnaire correctly. Therefore, a total of 1,109 respondents were able to correctly provide information about their most recently visited locations on the Google map. However, a lot of respondents did not correctly pinpoint on their 
departure and destination points. Instead of pointing on their actual departure location such as their home, place of work, or holyday home, more than half of the respondents pointed on the entrance to (or the edge of) the forest. In addition, about 100 respondents were removed as their destination or departure points were found outside of Denmark in nearby countries such as Sweden or Germany. Finally, 481 individuals were able to complete the questionnaire and correctly pinpoint on the required sites and become legible for our choice analysis. In general, our sample can be considered representative in terms of gender and region (see table 1), slightly overrepresented by young people, people with tertiary education, and low income.

\section{Table 1}

Descriptive statistics of sociodemographic characteristics of respondents

\begin{tabular}{|c|c|c|c|c|}
\hline Variable & Category & Expected $^{3}$ & Observed & P-value (chi) \\
\hline \multirow[t]{2}{*}{ Gender } & Female & 239 & 256 & 0.123 \\
\hline & Male & 242 & 225 & \\
\hline \multirow[t]{3}{*}{ Age } & $18-34$ & 148 & 165 & 0.041 \\
\hline & $35-49$ & 145 & 155 & \\
\hline & $50-70$ & 188 & 161 & \\
\hline \multirow[t]{4}{*}{ Education } & Primary & 99 & 37 & 0.000 \\
\hline & Secondary & 46 & 68 & \\
\hline & Vocational & 184 & 134 & \\
\hline & Tertiary $^{\mathrm{a}}$ & 152 & 242 & \\
\hline \multirow{4}{*}{$\begin{array}{l}\text { Gross annual } \\
\text { income }\end{array}$} & Below 200 thousand DKK & 96 & 151 & 0.000 \\
\hline & $200-400$ thousand DKK & 172 & 211 & \\
\hline & $400-600$ thousand DKK & 83 & 49 & \\
\hline & Above 600 thousand DKK & 130 & 70 & \\
\hline \multirow[t]{5}{*}{ Region } & Hovedstaden & 150 & 165 & 0.018 \\
\hline & Sjælland & 70 & 49 & \\
\hline & Syddanmark & 102 & 107 & \\
\hline & Midtjylland & 109 & 122 & \\
\hline & Nordjylland & 49 & 38 & \\
\hline
\end{tabular}

${ }^{3}$ DANMARKS STATISTIK: http://www.statistikbanken.dk. The 'Expected' sample reflects what a representative sample (of 481 people) would look like based on official statistics 
a Tertiary education includes medium level 'further' education (like Bachelor, Nurse, or High school teacher) and higher education levels (like Master and PhDs).

The questionnaire also contained questions regarding recreational activities and purposes of visiting forests. As shown in figure 1, most of the respondents make forest trips for walking activities and nature experience. Quite a lot of them indicated visiting forests for socialization (getting together with family, friends, or other people) and to obtain peace and quietness. Very few use forests for running, biking, or playing with children. They also mentioned mushroom picking as one of their activities in their recreational visits. These are more or less similar to the results from previous studies (e.g. see Jensen and Koch 2004, Smink 2011).

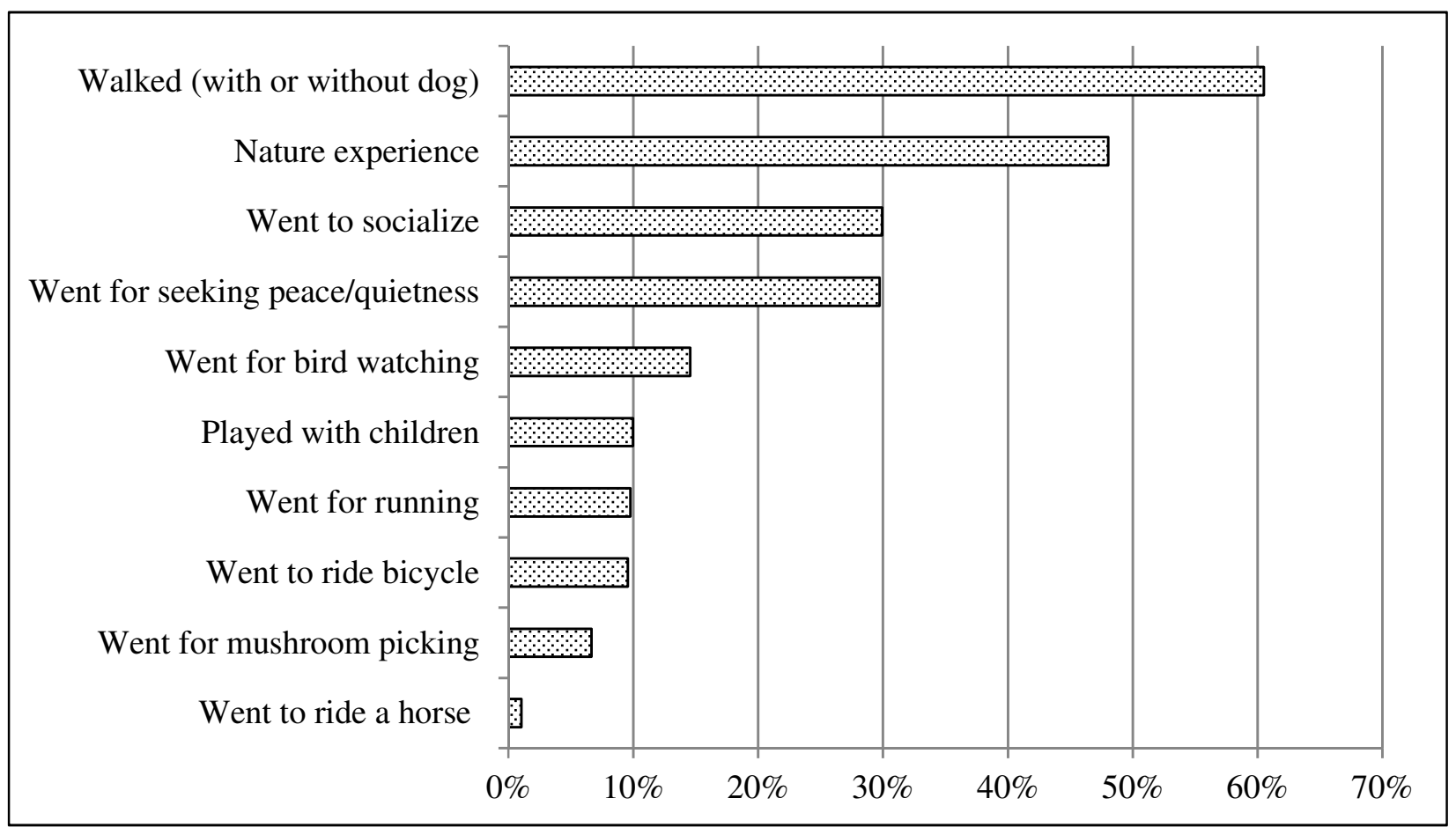

Figure 1: Recreational activities of forest visitors in their last visit

\subsection{Forest attributes and spatial data computation}

A spatial dataset that describe the characteristics of forests in Denmark is constructed based on the forest layer in the GeoDenmark geodatabase (DGA 2017). The Geodanmark database is managed by the Danish Geodata Agency and is part of a Danish effort to combine spatial data and make a common data infrastructure. The characteristics to enter the analysis are chosen on the basis of expectations from the literature as described in section 2 and 3. 
Forests that are less than 20 meters apart are combined into a single forest, to consider them as relevant alternatives. Forests smaller than 0.5ha, are removed from the dataset as they are considered as groves rather than forests. The characteristics of each forest site are found by combining spatial data from different sources using the R environment and the R packages rgdal and rgeos (R Core R-Core-Team 2016, Bivand et al. 2016a, Bivand and Rundel 2016b). The data for each attribute are described as follows:

Forest area: The size of each forest area are calculated using the gArea function in rgeos (Bivand and Rundel 2016b). We expect the quality of forest recreational experience to be a function of size and that it will increase with the size of the forest, due to increased recreational trip options, a possibility of a more pronounced "sense of nature" and less potential congestion.

Forest area form (shape): The forest area form is calculated by comparing the total area of a forest to the minimum spatial square that the forest would fit in. A forest form value close to one would indicate a forest which is close to a square shape (and more coherent) while a forest form value close to zero indicates a scattered forest shape. In the econometric modelling it is treated as dummy ( 1 if the ratio is greater than 0.5 and 0 otherwise).

Forest density: The forest density measure is created by combining the GeoDenmark forest layer with the CORINE land cover data on tree cover density (EEA 2014). A high density value of the forest area would indicate a more dense forest with a high tree stand count.

Species composition: The dominant tree species are identified for each forest. The forest sites are merged with a grid point dataset with a resolution of $25 * 25$ meters based on the tree type LIDAR satellite image from Schumacher (2014). The LIDAR satellite image differentiates between coniferous forests, broadleaved forests, and mixed forests. The distribution of grid-points falling inside each forest is created and the proportions of each type are calculated. The forest type calculated for each forest site is entered into the econometric model as a dummy variable ( 1 if the proportion is greater than half).

Other nature features: The forest dataset are merged with spatial data on lakes and wetland areas from the GeoDenmark geodatabase (DGA 2017). Lakes and wetlands within a distance of 20 meters of the forest are considered part of the forest. These are also treated as dummies in the modelling capturing effect of presence in the forest.

Historical sites: The number of historical sites within each forest is calculated based on data from the open spatial data source. The sites are limited to large constructions which a visitor would discover and recognize while visiting the forest. These historical sites mainly cover old hill tombs, old ramparts, castle and fortification ruins and various memorials of historical importance. This is also coded as dummy (1 if historical sites are present in the forest and 0 if not). 
Terrain difference: The terrain of the forest is approximated by finding the difference between the lowest and the highest point of the forest. Data are based on a terrain line shapefile from the open GeoDanmark database. Note that Denmark is mostly flat compared to most regions around the world and that terrain difference is likely to be perceived as something that would add to the recreational experience, given the general undersupply of terrain difference throughout the country. This is also taken as dummy ( 1 if terrain difference is greater than $30 \mathrm{~m}$, the mean value and 0 if lower).

State forest: The state owned forest data are merged with the forest layer from GeoDenmark (DGA 2017). In Denmark, private forests have restrictions on recreation access that are not practiced in state owned forests (see Campbell et al. 2013) which we believe could impact the recreational experience.

Distance: The Euclidian distance is calculated from all departure points to all forests within $30 \mathrm{~km}$ of radius. Distance to the last visited forest is calculated in a similarly way. Network distance calculations are not applied given the extensive number of distance calculations and the technical error it might introduce due to an incomplete data on road network at low level roads such as country lanes and gravel roads. Distance is a key variable in the analysis, which we expect will affect the recreational value negatively as it implies a cost.

The mean value of these attributes is reported in table 2 below. As shown in the table, most of the visitors made their trips to larger forests and forests dominated by broadleaved species. In addition, most visitors preferred recreating in forests which have wetlands or lakes, historical sites, have terrain difference (higher than $30 \mathrm{~m})$, or are owned by the state.

\section{Table 2}

The mean value of attributes in overall forests and visited sites

\begin{tabular}{lllll}
\hline Variable & Forest above 10 ha & Last visit & Second last visit & Third last visit \\
\hline Area in ha & 85 & 642 & 757 & 576 \\
Area-form & 0.21 & 0.18 & 0.15 & 0.15 \\
Density & 83 & 82 & 84 & 82 \\
Pro. of broadleaved & 0.52 & 0.70 & 0.68 & 0.69 \\
Wetland & 0.36 & 0.57 & 0.62 & 0.60 \\
Lakes & 0.33 & 0.71 & 0.72 & 0.71 \\
State owned & 0.13 & 0.46 & 0.52 & 0.49 \\
Historical sites & 0.37 & 0.72 & 0.75 & 0.72 \\
Terrain difference & 0.19 & 0.55 & 0.55 & 0.55 \\
Distance & - & 3.52 & 3.50 & 3.57 \\
\hline
\end{tabular}




\subsection{Selection of alternatives}

In principle, any forest in Denmark could be considered as an option for a visit and thus part of the individual's recreational choice set. However, distance will in practice limit the possibility of making trips to all forests and hence consideration of the full choice set. In our sample, $97 \%$ of the trips were within $30 \mathrm{~km}$; and DØRS (2014) reported the majority of forest trips being within a travel distance of below $50 \mathrm{~km}$, and only 7\% were above this. Consequently, we only considered alternative forest sites to be within $30 \mathrm{~km}$ from an individual's departure points. Within the $30 \mathrm{~km}$ radius, we identified an average number of 2,811 (minimum 530 and maximum 4,979) forest sites per respondent. It can be argued that a forest needs a minimum size to be relevant for recreation. Therefore, we tested a further reduction of the number of relevant forests by considering forests above 10ha. This reduced the number of alternatives to 291 on average (minimum 51 and maximum 668) per respondent. With large choice sets, analysis of choice making will become difficult both in terms of data arrangement and statistical computation.

Commonly, researchers follow two strategies of alternative reduction: site aggregation and random sampling (see Parsons and Kealy 1992, Parsons and Needelman 1992, Feather 1994, Termansen et al. 2004). Choice sets defined by aggregation are constructed through combining similar alternatives to be defined in some geographical boundary (like regions or counties) by taking an average value of the characteristics (Parsons and Kealy 1992, Feather 1994). Feather (1994) pointed out that such strategy would be preferable when data are only available at some aggregated level (e.g. regional data) or when there is little or no information available for some alternatives. The limitation of using aggregated choice sets is that it might lead to biased estimates due to the fact that an average value would not represent the actual attribute of a given site (Parsons and Kealy 1992, Parsons and Needelman 1992). In other words, spatial aggregation can obscure unique features of specific recreational sites (Horne et al. 2005). Consequently, it was not considered reasonable for this case, where the interest is in the details of the choice of the individual. The simple random sampling method is suggested to be used when data are available for each specific site and the full choice set is very large. This sampling method can also be used after choice sets are defined to be within certain spatial boundaries (Parsons and Hauber 1998).

Therefore, we apply the simple random sampling technique to select the alternative sites which together with the actual visited forests will form the choice sets. First, we examine the significance and consistency of parameter estimates with different number of alternatives by running conditional logit (CL) estimations using the most recently visited forest. The sampling and estimation procedure is sequentially repeated multiple times for a choice set with 5, 10, 50, and 100 alternatives. From this we conclude that models including 50 alternatives provide consistent estimates. Then, we estimate a random parameter logit (RPL) model by taking 50 alternatives for each of the visited forests utilizing the panel structure of the three reported visits. 


\subsection{Model specification}

The recreational use of nature areas, such as forests can be evaluated by considering the travel cost of individuals. The travel cost models usually have two components: a site preference model and a count model which in combination can be used to analyse welfare changes associated with quality changes (Feather et al. 1995, Hausman et al. 1995, Herriges et al. 1999, Parsons et al. 1999, Bujosa and Riera 2010, Raguragavan et al. 2013). This approach is useful to estimate demand over a given period of time or a season (Feather et al. 1995, Bujosa and Riera 2010). Furthermore, preference studies have been conducted through combined use of revealed and SP data (Adamowicz et al. 1994, Azevedo et al. 2003, Eom and Larson 2006, Whitehead et al. 2008). The present study is conducted based on revealed data from reported visited sites, the characteristics of which are identified by using high resolution spatial data allowing us to obtain site specific characteristics. The focus is on estimating preferences and hence we do not carry out welfare estimates by relating it to count data modelling (see Hausman et al. 1995). The choice of recreational sites is modelled using the random utility maximization framework (McFadden 1974, 1978, Boxall et al. 1996, Train 1998). Hence, in our case, the choice analysis is undertaken based on the CL and RPL modelling, where the RPL is employed mainly to account for preference heterogeneity (Train 2003).

When alternatives are randomly sampled, the standard logistic formulation has to be modified by including an adjustment term which is the probability of generating the alternative, in order to yield consistent parameter estimates, provided some conditionality properties are being satisfied (McFadden 1978). Thus, the probability of alternative $i$ to be chosen by individual $n$ is given by:

$P_{i n}=\frac{e^{V_{i n}+\ln \left(\pi_{n}\left(D_{n} \mid i\right)\right)}}{\sum_{j \in D} e^{V_{j n}+\ln \left(\pi_{n}\left(D_{n} \mid j\right)\right)}} ;$

where $V_{i n}$ represents the deterministic component of utility, in our case, a function of forest characteristics and sociodemographic variables. The term $\pi_{n}\left(D_{n} \mid i\right)$ is the probability of generating an alternative set $D_{n}$ given the actual choice $i$ under the sampling scheme.

However, with simple random sampling where the probability of each non-chosen alternative is equal, no adjustment would be required (Lemp and Kockelman 2012). Estimation on the subsample alternatives can be done the same way as estimation of full size choice set (Frejinger et al. 2009, Lemp and Kockelman 2012). This is the case for the CL model. For an RPL model, approximate adjustments may be required. However, no single approximation seems to be superior. As our results from an RPL model and a CL turn out to be quite similar except for the RPL model allowing for heterogeneity, it becomes a minor issue in our case; and consequently, we instead present both RPL and CL results. 


\section{Results}

\subsection{Importance of the number of randomly selected alternatives}

Because we apply simple random sampling of alternatives, a relevant question is how many alternatives is enough to be considered in the choice modelling. To investigate this, we evaluate the sensitivity of estimates over an increasing number of sampled alternatives $(5,10,50$, and 100). Therefore, the CL model is used to perform this evaluation i.e. consistency of parameters over repeated sampling of different number of alternatives for which the RPL would not be feasible. The sampling and estimation process is sequentially repeated 100 times. Notice that we considered forests larger than 10 hectare $^{4}$. The estimation results are illustrated with mean values corresponding to each sample size and distributions of the parameter estimates in kernel density graphs (see appendix A and C).

With regard to sampling of alternatives we observe two things. First, as the sample size of alternatives increases variables become significant; i.e. the explanatory power of the variables will improve as the number of non-chosen alternatives increases. For instance, the parameter for 'forest density' was estimated insignificant when we take 10 or less alternatives but becomes significant with 50 alternatives. Second, with large sample of alternatives, the variation in estimates from repeated sampling becomes smaller.

\subsection{Estimation based on random parameter logit model}

To evaluate which forest characteristics people prefer, we estimated a RPL model in order to be able to model the potential heterogeneity of preferences in our data. Notice that all the parameters except distance are assumed to follow a normal distribution. As shown in table 3, most of the attributes are estimated significant with the expected signs. The random sampling of 50 alternatives and subsequent estimation of parameters is repeated 10 times and we only report the result with the highest 'maximum log likelihood' value. The parameter estimates over the 10 estimations are consistent in significance and sign; but differ somewhat in magnitude (see appendix B for the min. and max. estimates from the ten repeated estimations).

The size of a forest (area) contributes positively to the recreational value, as expected, with a decreasing marginal effect. This variable is considered in a log transformation rather than a linear measure, for better modelling performance and consistency with the assumption of decreasing marginal utility. The proportion of land area covered by dominantly broadleaved forest is also significant with a positive impact on the recreational value. In contrast, forest density reduces the recreational importance - i.e. visually dense forests are less likely chosen for recreational trips. The presence of historical sites increases the probability of a forest being visited.

\footnotetext{
${ }^{4}$ A model with all forests (i.e. including smaller forests of 0.5 ha threshold) was tested and provided similar results. However, for computational issues and because as Table 2 shows, the small forests are probably not realistic alternatives, we chose the limit of 10 ha.
} 
Similarly, forests with a terrain difference of greater than $30 \mathrm{~m}$ are more likely to be preferred for recreation. State owned forests are found to be preferred over privately owned forests. The negative sign of 'distance' implies that forests located farther away are less preferred as expected. In this modelling, the presence of other nature features, i.e. lakes and wetlands are not significant. Similarly, the variable 'area form' is not significant. This insignificance, at the mean value, could partly be attributed to the significant standard deviation i.e. heterogeneity in this variable. The standard deviations of the significant variables are also estimated significant implying preference heterogeneity among respondents.

In addition, we evaluate the interactions between distance and other variables such as age, mode of transport i.e. whether traveling on foot or car, and nature experience as a purpose of recreation. The interaction of distance with 'traveling on foot' is significant with its expected negative sign, while the interaction with 'traveling by car' is positive. The result shows that forests located at farther distance are less preferable by visitors traveling on foot, while visitors who used personal cars are less affected by distance. Forest visitors who had the purpose of nature experience are willing to travel longer compared to those traveling for other purposes.

Table 3

Estimation result based on the random parametric logit

\begin{tabular}{lllllll}
\hline Variable & \multicolumn{3}{c}{ Basic RPL } & \multicolumn{3}{c}{ RPL with interaction } \\
\cline { 2 - 7 } & Est. & SE & P-value & Est. & SE & P-value \\
\hline Ln area & $1.21^{* * * *}$ & 0.08 & 0.000 & $1.23^{* * *}$ & 0.09 & 0.000 \\
Area-form & 0.23 & 0.20 & 0.259 & 0.24 & 0.21 & 0.252 \\
Density & $-0.02^{*}$ & 0.01 & 0.073 & $-0.02^{* *}$ & 0.01 & 0.036 \\
Pro. of broadleaves & $0.67^{* * *}$ & 0.18 & 0.000 & $0.63^{* * *}$ & 0.18 & 0.001 \\
Availability of wetlands & -0.16 & 0.15 & 0.275 & -0.10 & 0.16 & 0.535 \\
Availability lakes & 0.25 & 0.15 & 0.102 & $0.31^{* *}$ & 0.16 & 0.050 \\
State owned & $0.82^{* * *}$ & 0.18 & 0.000 & $0.82^{* * *}$ & 0.19 & 0.000 \\
Presence of historical sites & $0.78^{* * *}$ & 0.18 & 0.000 & $0.76^{* * *}$ & 0.19 & 0.000 \\
Terrain difference & $0.71^{* * *}$ & 0.18 & 0.000 & $0.77^{* * *}$ & 0.20 & 0.000 \\
Distance & $-0.56^{* * *}$ & 0.02 & 0.000 & $-0.81^{* * *}$ & 0.07 & 0.000 \\
\hline Distance * age & - & - & - & 0.002 & 0.001 & 0.139 \\
Distance * foot & - & - & - & $-0.24^{* * *}$ & 0.06 & 0.000 \\
Distance * car & - & - & - & $0.31^{* * *}$ & 0.05 & 0.000
\end{tabular}




\begin{tabular}{lllllll} 
Distance * nature viewing & - & - & - & $0.10^{* * *}$ & 0.03 & 0.003 \\
\hline Standard deviations & & & & & & \\
\hline Ln area & $0.56^{* * *}$ & 0.08 & 0.000 & $0.52^{* * *}$ & 0.09 & 0.000 \\
Area-form & $1.20^{* * *}$ & 0.33 & 0.000 & $1.12^{* * *}$ & 0.36 & 0.002 \\
Density & $0.02^{* *}$ & 0.01 & 0.041 & $0.02^{* *}$ & 0.01 & 0.015 \\
Pro. of broadleaves & $1.16^{* * *}$ & 0.33 & 0.000 & $-0.76^{*}$ & 0.45 & 0.093 \\
Availability of wetlands & 0.17 & 0.53 & 0.755 & 0.36 & 0.48 & 0.449 \\
Availability lakes & 0.07 & 0.51 & 0.888 & 0.08 & 0.50 & 0.871 \\
State owned & $0.90^{* *}$ & 0.36 & 0.012 & $0.90^{* *}$ & 0.41 & 0.026 \\
Presence of historical sites & $1.20^{* * *}$ & 0.33 & 0.000 & $1.07^{* * *}$ & 0.36 & 0.003 \\
Terrain difference & $1.57^{* * *}$ & 0.29 & 0.000 & $1.82^{* * *}$ & 0.30 & 0.000 \\
Final LL & -1124.24 & & & -1021.07 & & \\
\hline
\end{tabular}

***, ${ }^{* *},{ }^{*}$ significance level at $1 \%, 5 \%$, and $10 \%$ respectively

\section{Discussion}

Our motivation to undertake this study was to evaluate preferences of forest visitors in a revealed preference approach, using visited sites and to distinguish the main attributes that can affect the recreational use of forests. Hence, we investigated the effect of forest characteristics including: distance, forest area, area-form, forest density, tree species types, availability of other nature features (lakes and wetlands), terrain difference, presence of historical sites, and state ownership. These attributes were chosen based on literature reviews and availability of spatial data. The analysis was conducted using the standard random utility maximization framework (McFadden 1974) in which the utility was set as a function of the forest attributes. The choice sets of each respondent were defined to include all forest sites within a distance of $30 \mathrm{~km}$ from the respondent's departure location. To avoid overly large choice sets, we considered a reasonable number of alternatives using simple random sampling. As a result, the study also provides empirical evidence to the issue in determining number of alternatives required for consistent estimates.

As expected, distance is one of the main determinants that influence forest site choice. Its significant negative parameter estimate indicates how forests in short distance to residential areas are important for recreational trips. In addition, large size forests, forests with a greater proportion of broadleaved species and with lower stand density are more preferable for recreational visits. The estimate of area in its log transformation implies its positive impact with a diminishing marginal effect. Such an effect is also shown in previous similar 
studies (e.g. Scarpa et al. 2000b, Termansen et al. 2013). Forests with a greater proportion of broadleaved species are more preferred for recreational uses. Stand density is found to impact the likelihood of a forest being chosen negatively. It can be noticed that forest area, and stand density could reflect the wilderness of a forest and visibility. Yet, the recreational value of such wilderness forest will be reduced when the forest becomes too dense. Previously, some studies showed that forests with lower visual density could provide better scenic views and a sense of safety (Kaplan and Kaplan 1989, Heyman et al. 2011, Heyman 2012) or better access (Varela et al. 2016). The dummy variable indicating presence of 'historical sites' is also significant implying that 'historical sites' is an important factor when people chose forest sites for recreation purposes. Likewise, forests with higher terrain difference are preferred over those having lower terrain difference (i.e. relatively flat landscapes). Denmark is a relatively flat landscape country and terrain difference might add variation to the landscape and enhance opportunities for scenic views. Moreover, state owned forests are found to significantly contribute to the recreational importance of forests. This is most probably due to difference in recreational access rights, where these are generally much better in state owned forests. Another explanation could perhaps be that private forests tend to be more intensively managed for commercial purposes which may reduce recreational values.

In addition, the interaction effects highlight some important implications. For instance, we found visitors travelling by foot to be more sensitive to distance than visitors who use car as means of transport. In addition, the interaction between distance and purpose of visit (e.g. nature experience) is significant; individuals who visit forests for nature experience are not much affected by longer distance.

So far, various studies (e.g. Skov-Petersen and Jensen 2004, Termansen et al. 2004, Zandersen et al. 2007, Termansen et al. 2008, Termansen et al. 2013) have been conducted to evaluate preferences and demand for forest recreation using RP data in the Danish context. For instance, Termansen et al. (2004) evaluated preferences considering many attributes including travel distance, forest area, fraction of broadleaved area, distance to coast, slope, fraction of wet area edge, nature and semi-nature area, and some recreational facility indicators (parking and information on marked nature trail). The current study adds knowledge to the existing literature in the context of analysing recreational values of forests, especially using RP data with spatial data complements. We include forest attributes that are useful from the management perspective. In addition, understanding the interaction effects would help to justify the desired recreational facilities and imply management options (Arnberger 2006). Furthermore, we provide an empirical result showing how large randomly selected alternatives should be considered to get consistent estimates. Previously, Nerella and Bhat (2004) suggested a minimum sample on one-eighth of the full choice set with simple random sampling technique to generate consistent estimates. But, we thought our estimates are already consistent enough without such larger sample size. If considering their suggestion, we would expect only improvements in efficiency of the estimates. 
To the end, it is worth to note a couple of limitations of the present paper. The first weakness is that we assume the most recently visited forest sites (i.e. 'chosen sites') to be representative of the respondent's 'stable' preferences. However, forest visitors can experience recreation in different locations for different purposes at different times. This becomes particularly important as data was collected in May 2015 thereby potentially incurring a spring seasonality bias (see Bartczak et al. 2011). The second issue is the exclusion of a sizable proportion of respondents. As mentioned earlier, our spatial data relies on respondent pinpointed locations of visited sites of which two-third of respondents fail to correctly indicate the 'destination' and 'departure' locations on the interactive map, probably due to misunderstanding of the instructions in the questionnaire. While this reduces the sample, we have no reason to believe it to be correlated with the last visits, and consequently we see no reason why this should bias the results.

\section{Conclusion}

Valuation of non-market environmental goods can be undertaken using both SP and RP approaches. But, due to limitations of the SP methods, related to the hypothetical nature; scholars recommend the use of RP when data are available (Adamowicz et al. 1994, Azevedo et al. 2003). Relying on such justification, the current study is conducted to analyse preferences for forest recreational sites using data from actual visits. Our analysis is performed by defining choice sets to included alternative forests within $30 \mathrm{~km}$ from departure locations. Such a definition is made to obtain more realistic choice sets and reliable estimates, as most forest trips are shorter than $30 \mathrm{~km}$. We presume inclusion of all forest sites with consideration of spatial data to be a more robust approach in addressing variation. The RP approach which involves integration of spatial data may insure more realistic choice modelling of forest recreation than the SP approach. The study is able to validate the findings from previous SP studies in terms of relative size and significance of attributes (e.g. distance, species composition, area, and stand density). In addition, more variables are included than what would usually be the case in SP studies.

Most of the included forest attributes are significant and relevant to raise important policy issues. Distance is found to play a crucial role in affecting choice of recreational forest location; and that is inflicted by mode of transport used. The implication is that forests need to be accessible within residential locations of visitors for more frequent trips, and that shall be considered in future afforestation plans. The positive value of a higher proportion of broadleaves would imply a need to increase the amount of broadleaves in future forest management and afforestation plans. Moreover, we are able to indicate the relevance of other features. For instance, we showed that presence of historical sites increases the recreational value of forests. That could imply the necessity of precautionary forest management rules which should account for preserving such sites. The 
other important insight is about impact of state ownership. State owned forests are more preferable, probably, due to the unrestricted recreational access policies applied in state forests.

Forest recreation studies in Denmark have been undertaken for long and thought to brought about changes in forest policies over time (Jensen and Koch 2004). We believe that our study can contribute to the existing knowledge regarding the critical evaluation of recreational values of forests in the country. It enables to justify the importance of different forest attributes and the necessity of taking consideration of non-market services in forest management policies and afforestation plans. This becomes of particular importance for the trade-offs with other ecosystem services and where to provide which: recreational quality depends both highly on the characteristics of a forest and its relative distance to people.

\section{Acknowledgement}

The first author acknowledges the funding from the Education, Audio-visual, and Culture Executive Agency (EACEA) of the European Commission under Erasmus Mundus Action 1 Doctoral Fellowship as part of the Erasmus Mundus Joint Doctoral Program "Forests and Nature for Society" (FONASO). The authors affiliated with Centre for Macro-ecology, Evolution and Climate acknowledge the funding from the Danish National Research Foundation (grant number DNRF96). 


\section{Appendix A}

Consistency of parameters from different sample size of alternatives; based on CL estimation by taking alternatives only corresponding to the most recently visited forest. Mean value of the coefficients from repeated ${ }^{5}$ sequential sampling and estimation.

\begin{tabular}{lrrrr}
\hline Variable & 5 alts & 10 alts & 50 alts & 100 alts \\
\hline Ln area & 0.87 & 0.85 & 0.82 & 0.80 \\
Area-form & 0.44 & 0.38 & 0.41 & 0.42 \\
Density & -0.01 & -0.01 & -0.01 & -0.01 \\
Pro. of broadleaves & 0.50 & 0.52 & 0.57 & 0.60 \\
Availability of wetlands & -0.07 & -0.10 & -0.16 & -0.17 \\
Availability lakes & 0.32 & 0.35 & 0.42 & 0.42 \\
State owned & 0.60 & 0.53 & 0.36 & 0.28 \\
Presence of historical & 0.70 & 0.68 & 0.63 & 0.65 \\
sites & & & & \\
Terrain difference & 0.60 & 0.60 & 0.66 & 0.69 \\
Distance & -0.37 & -0.39 & -0.45 & -0.47 \\
\hline
\end{tabular}

\section{Appendix B}

The variation in coefficients of significant variables from the sequentially repeated ${ }^{6}$ sampling (50 alternatives) and estimation process based on the RPL model

\begin{tabular}{lcc}
\hline Variable & Min. & Max. \\
\hline Ln area & 1.11 & 1.22 \\
Density & -0.02 & -0.01 \\
Pro. of broadleaves & 0.56 & 0.74 \\
State owned & 0.51 & 0.82 \\
Presence of historical sites & 0.78 & 1.07 \\
Terrain difference & 0.53 & 0.78 \\
Distance & -0.56 & -0.54 \\
\hline
\end{tabular}

\footnotetext{
${ }^{5}$ These are the mean values from the estimation performed 100 times.

${ }^{6}$ Sequential sampling and estimation preformed 10 times
} 


\section{Appendix C}
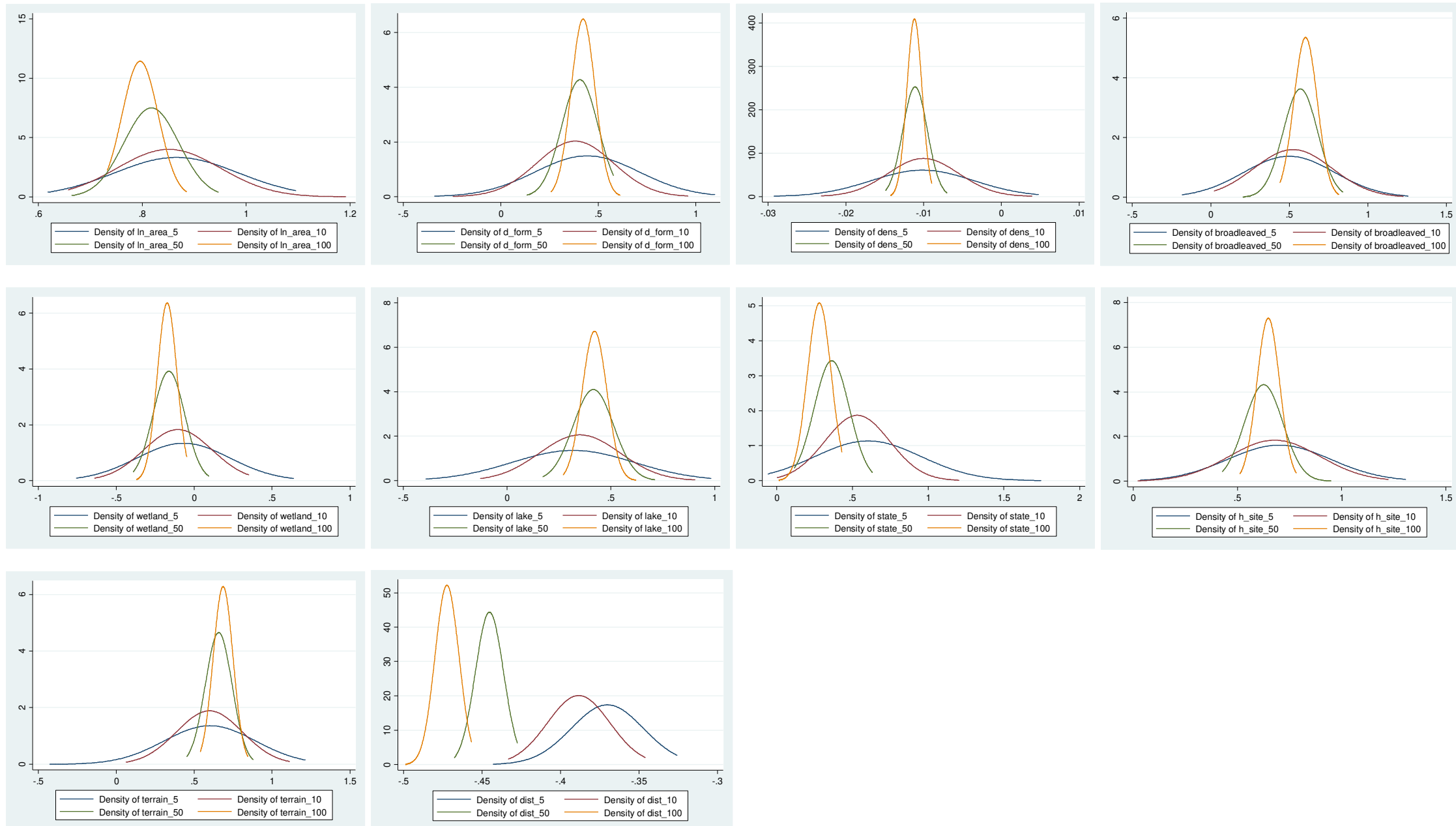

Distribution of coefficients from repeated estimation using the conditional logit model 


\section{References}

Abildtrup, J., S. Garcia, S. B. Olsen, and A. Stenger. 2013. Spatial Preference Heterogeneity in Forest Recreation. Ecological Economics 92:67-77.

Abildtrup, J., S. B. Olsen, and A. Stenger. 2014. Combining RP and SP Data while Accounting for Large Choice Sets and Travel Mode - an Application to Forest Recreation. Journal of Environmental Economics and Policy 4:177-201.

Adamowicz, W., J. Louviere, and M. Williams. 1994. Combining Revealed and Stated Preference Methods for Valuing the Environmental Amenities. Environmental Economics and Management 26:271-292.

Arnberger, A. 2006. Recreation use of urban forests: An inter-area comparison. Urban Forestry \& Urban Greening 4:135-144.

Axelsson-Lindgren, C., and G. Sorte. 1987. Public response to differences between visually distinguishable forest stands in a recreation area. Landscape and Urban Planning 14:211-217.

Azevedo, C. D., J. A. Herriges, and C. L. Kling. 2003. Combining Revealed and Stated Preferences: Consistency Tests and Their Interpretations American Journal of Agricultural Economics 85:525-537.

Baerenklau, K. A., A. González-Cabán, C. Paez, and E. Chavez. 2010. Spatial allocation of forest recreation value. Journal of Forest Economics 16:113-126.

Bakhtiari, F., J. B. Jacobsen, and F. S. Jensen. 2014. Willingness to travel to avoid recreation conflicts in Danish forests. Urban Forestry \& Urban Greening 13:662-671.

Bartczak, A. 2015. The role of social and environmental attitudes in non-market valuation. Forest Policy and Economics 50:357-365.

Bartczak, A., J. Englin, and A. Pang. 2011. When are Forest Visits Valued the Most? An Analysis of the Seasonal Demand for Forest Recreation in Poland. Environmental and Resource Economics 52:249-264.

Bell, S., L. Tyrväinen, T. Sievänen, U. Pröbstl, and M. Simpson. 2007. Outdoor Recreation and Nature Tourism: A European Perspective. Living Reviews in Landscape Research 1:1-46.

Bivand, R., T. Keitt, and B. Rowlingson. 2016a. rgdal: Bindings for the Geospatial Data Abstraction Library. R package version 1.1-10. URL https://CRAN.R-project.org/package=rgdal.

Bivand, R., and C. Rundel. 2016b. rgeos: Interface to Geometry Engine - Open Source (GEOS). R package version 0.3-19. URL https://CRAN.R-project.org/package=rgeos.

Bjerke, T., T. Østdahl, C. Thrane, and E. Strumse. 2006. Vegetation density of urban parks and perceived appropriateness for recreation. Urban Forestry \& Urban Greening 5:35-44. 
Boxall, P. C., D. O. Watson, and J. Englin. 1996. Backcountry recreationalists' valuation of forest and park management features in wilderness parks of the western Canadian Shield. Canadian Journal of Forest Resources 26:982-990.

Bujosa, A., and A. Riera. 2009. Environmental diversity in recreational choice modelling. Ecological Economics 68:2743-2750.

Bujosa, A., and A. Riera. 2010. Estimating the aggregate value of forest recreation in a regional context. Journal of Forest Economics 16:205-216.

Campbell, D., R. Scarpa, and W. G. Hutchinson. 2008. Assessing the spatial dependence of welfare estimates obtained from discrete choice experiments. Letters in Spatial and Resource Sciences 1:117-126.

Campbell, D., S. E. Vedel, B. J. Thorsen, and J. B. Jacobsen. 2013. Heterogeneity in the WTP for recreational access: distributional aspects. Journal of Environmental Planning and Management 57:1200-1219.

Christie, M., N. Hanley, and S. Hynes. 2007. Valuing enhancements to forest recreation using choice experiment and contingent behaviour methods. Journal of Forest Economics 13:75-102.

DFNA. 2002. The Danish national forest programme in an international perspective. MINISTRY OF THE ENVIRONMENT: Danish Forest and Nature Agency.

DGA. 2017. Danish Geodata Agency (GeoDanmark). URL http://www.geodanmark.dk/

Dhakal, B., R. T. Yao, J. A. Turner, and T. Barnard. 2012. Recreational users' willingness to pay and preferences for changes in planted forest features. Forest Policy and Economics 17:34-44.

Douglass, R. W. 1982. Forest Recreation, 3rd Edition. Pergamon Press, New York.

DØRS. 2014. De Økonomiske Råd. Dansk Økonomi, efterår 2014, URL https://www.dors.dk/.

Edwards, D., M. Jay, F. S. Jensen, B. Lucas, M. Marzano, C. Montagné, A. Peace, and G. Weiss. 2012a. Public preferences for structural attributes of forests: Towards a pan-European perspective. Forest Policy and Economics 19:12-19.

Edwards, D. M., M. Jay, F. S. Jensen, B. Lucas, M. Marzano, C. Montagné, A. Peace, and G. Weiss. 2012 b. Public Preferences Across Europe for Different Forest Stand Types as Sites for Recreation. Ecology and Society 17:1-11.

EEA. 2014. European Environment Agency. The Corine Land Cover,URL http://land.copernicus.eu/paneuropean/corine-land-cover.

Eom, Y.-S., and D. M. Larson. 2006. Improving environmental valuation estimates through consistent use of revealed and stated preference information. Journal of Environmental Economics and Management 52:501-516.

Feather, P. M. 1994. Sampling and Aggregation Issues in Random Utility Model Estimation. American Journal of Agricultural Economics 76:772-780. 
Feather, P. M., D. Hellerstein, and T. Tomasi. 1995. A Discrete-Count Model of Recreational Demand. Journal of Environmental Economics and Management 29:214-227.

Filyushkina, A., F. Agimass, T. Lundhede, N. Strange, and J. B. Jacobsen. 2017. Preferences for variation in forest characteristics: Does diversity between stands matter? Ecological Economics 140:22-29.

Frejinger, E., M. Bierlaire, and M. Ben-Akiva. 2009. Sampling of alternatives for route choice modeling. Transportation Research Part B 43 984-994.

Giergiczny, M., M. Czajkowski, T. Żylicz, and P. Angelstam. 2015. Choice experiment assessment of public preferences for forest structural attributes. Ecological Economics 119:8-23.

Gundersen, V. S., and L. H. Frivold. 2008. Public preferences for forest structures: A review of quantitative surveys from Finland, Norway and Sweden. Urban Forestry \& Urban Greening 7:241-258.

Haener, M. K., P. C. Boxall, and W. L. Adamowicz. 2001. Modeling Recreation Site Choice: Do Hypothetical Choices Reflect Actual Behavior? American Journal of Agricultural Economics 83: 629-642.

Hausman, J. 2012. Contingent Valuation: From Dubious to Hopeless. Journal of Economic Perspectives 26:4356.

Hausman, J. A., G. K. Leonard, and D. McFadden. 1995. A utility-consistent, combined discrete choice and count data model Assessing recreational use losses due to natural resource damage. Journal of Public Economics 56:1-30.

Herriges, J. A., C. L. Kling, and D. J. Phaneuf. 1999. Corner Solution Models of Recreation Demand: A Comparison of Competing Frameworks: in Herriges, J. A. , and C. L. Kling (eds.), Valuing Recreation and the Environment; Edward Elgar, Cheltenham.163-197.

Heyman, E. 2012. Analysing recreational values and management effects in an urban forest with the visitoremployed photography method. Urban Forestry \& Urban Greening 11:267-277.

Heyman, E., B. Gunnarsson, M. Stenseke, S. Henningsson, and G. Tim. 2011. Openness as a key-variable for analysis of management trade-offs in urban woodlands. Urban Forestry \& Urban Greening 10:281-293.

Horne, P., P. C. Boxall, and W. L. Adamowicz. 2005. Multiple-use management of forest recreation sites: a spatially explicit choice experiment. Forest Ecology and Management 207:189-199.

http://eng.svana.dk/nature/forestry/. 2017. Forestry: Facts on the Danish forests. Retrived on 28 March 2017.

Hynes, S., N. Hanley, and R. Scarpa. 2008. Effects on Welfare Measures of Alternative Means of Accounting for Preference Heterogeneity in Recreational Demand Models. American Journal of Agricultural Economics 90:1011-1027.

Hörnsten, L., and P. Fredman. 2000. On the distance to recreational forests in Sweden. Landscape and Urban Planning 51:1-10. 
Jacobsen, J. B., and B. J. Thorsen. 2010. Preferences for site and environmental functions when selecting forthcoming national parks. Ecological Economics 69:1532-1544.

Jensen, F. S., and N. E. Koch. 2004. Twenty-five Years of Forest Recreation Research in Denmark and its Influence on Forest Policy. Scandinavian Journal of Forest Research 19:93-102.

Kaplan, R., and S. Kaplan. 1989. The Experience of Nature: A Psychological Perspective, Cambridge University Press, Cambridge

Lemp, J. D., and K. M. Kockelman. 2012. Strategic Sampling for Large Choice Sets in Estimation and Application. Transportation Research Part A 46:602-613.

Lindhagen, A., and L. Hörnsten. 2000. Forest recreation in 1977 and 1997 in Sweden: changes in public preferences and behaviour. Forestry 73:143-153.

McFadden, D. 1974. Conditional logit analysis of qualitative choice behavior. In: Zarembka, P. (Ed.). Frontiers in Econometrics IV:105-142.

McFadden, D. 1978. Modeling the choice of residential location. In: Karlqvist, A., Lundqvist, L., Snickbars, F., Weibull, J. (Eds.), Spatial Interaction Theory and Residential Location. North-Holland, Amsterdam.7596.

Nerella, S., and C. R. Bhat. 2004. Numerical analysis of effect of sampling of alternatives in discrete choice models. Transportation Research Records 1894:11-19.

Nielsen, A. B., S. B. Olsen, and T. Lundhede. 2007. An economic valuation of the recreational benefits associated with nature-based forest management practices. Landscape and Urban Planning 80:63-71.

Parsons, G. R., and A. B. Hauber. 1998. Spatial Boundaries and Choice Set Definition in a Random Utility Model of Recreation Demand. Land Economics 74:32-48.

Parsons, G. R., P. M. Jakus, and T. Tomasi. 1999. A Comparison of Welfare Estimates from Four Models for Linking Seasonal Recreational Trips to Multinomial Logit Models of Site Choice. Journal of Environmental Economics and Management 38:143-157.

Parsons, G. R., and M. J. Kealy. 1992. Randomly Drawn Opportunity Sets in a Random Utility Model of Lake Recreation. Land Economics 68:93-106.

Parsons, G. R., and M. S. Needelman. 1992. Site Aggregation in a Random Utility Model of Recreation. Land Economics 68:418-433.

Petucco, C., J. P. Skovsgaard, and F. S. Jensen. 2013. Recreational preferences depending on thinning practice in young even-aged stands of pedunculate oak (Quercus roburL.): comparing the opinions of forest and landscape experts and the general population of Denmark. Scandinavian Journal of Forest Research 28:668-676. 
R-Core-Team. 2016. R: A language and environment for statistical computing. R Foundation for Statistical Computing, Vienna, Austria. URL https://www.R-project.org/.

Raguragavan, J., A. Hailu, and M. Burton. 2013. Economic valuation of recreational fishing in Western Australia: statewide random utility modelling of fishing site choice behaviour. Australian Journal of Agricultural and Resource Economics 57:539-558.

Ribe, R. G. 1989. The Aesthetics of Forestry: What Has Empirical Preference Research Taught Us? Environmental Management 31:55-74.

Scarpa, R., W. G. Hutchinsonc, S. M. Chiltond, and J. Buongiornoe. 2000a. Importance of forest attributes in the willingness to pay for recreation: a contingent valuation study of Irish forests. Forest Policy and Economics 1:315-329.

Scarpa, R., W. G. Hutchinsonc, S. M. Chiltond, and J. Buongiornoe. 2000b. Valuing the recreational benefits from the creation of nature reserves in Irish forests. Ecological Economics 33:237-250.

Schumacher, J. 2014. Assessing forest resources in Denmark using wall-to-wall remote sensing data. Copenhagen: University of Copenhagen, Department of Geosciences and Natural Resource Management.

Skov-Petersen, H. 2002. GIS-based modeling of car-borne visits to Danish Forests.pdf. Conference proceeding:233-239.

Skov-Petersen, H., and F. S. Jensen. 2004. Assessing recreation in the Danish nature - present experiences, towards a future monitoring system. Working Papers of the Finnish Forest Research Institute 2.

Smink, C. K. 2011. Forests and Recreation - New Functions of Afforestation as Seen in Denmark; in Ritter, E. and Dauksta, D. (Eds) New perspectives on people and forests. World Forests IX. World Forests IX:8794.

Tahvanainen, L., L. Tyrvainen, M. Ihalainen, N. Vuorela, and O. Kolehmainen. 2001. Forest management and public preference - visual versus verbal information. Landscape and Urban Planning 53:53-70.

Termansen, M., C. J. McClean, and F. S. Jensen. 2013. Modelling and mapping spatial heterogeneity in forest recreation services. Ecological Economics 92:48-57.

Termansen, M., C. J. McClean, and H. Skov-Petersen. 2004. Recreational site choice modelling using highresolution spatial data. Environment and Planning 36:1085-1099.

Termansen, M., M. Zandersen, and C. J. McClean. 2008. Spatial substitution patterns in forest recreation. Regional Science and Urban Economics 38:81-97.

Train, K. E. 1998. Recreation Demand Models with Taste Differences over People. Land Economics 74:230239.

Train, K. E. 2003. Discrete Choice Methods with Simulation. Cambridge University Press, New York. 
van der Horst, D. 2006. Spatial cost-benefit thinking in multi-functional forestry; towards a framework for spatial targeting of policy interventions. Ecological Economics 59:171-180.

Varela, E., J. B. Jacobsen, and R. Mavsar. 2016. Social demand for multiple benefits provided by Aleppo pine forest management in Catalonia, Spain. Regional Environmental Change 17:539-550.

Whitehead, J. C., S. K. Pattanayak, G. L. Van Houtven, and B. R. Gelso. 2008. Combining Revealed and Stated Preference Data to Estimate the Nonmarket Value of Ecological Services: An Assessment of the State of the Science. Journal of Economic Surveys 22:872-908.

Zandersen, M., M. Termansen, and F. S. Jensen. 2007. Evaluating approaches to predict recreation values of new forest sites. Journal of Forest Economics 13:103-128. 